Maria Carmen de Frias e Gouveia (D) Universidade de Coimbra / CELGA-ILTEC mariacarmen.defriasegouveia@gmail.com

\title{
Aquisição e uso das formas de tratamento em português - língua estrangeira ${ }^{1}$
}

\section{Resumo:}

O objectivo principal do presente trabalho é analisar o modo como o complexo sistema de formas de tratamento (e seu uso) é apresentado aos aprendentes de Português como língua estrangeira.

Após uma breve consideração, de cariz mais teórico, sobre a delicadeza em Linguística, a dêixis social e a sua relação com as formas de tratamento, apresenta-se esse sistema em Português (europeu e brasileiro), como ponto de partida para a análise da descrição que as gramáticas e materiais didácticos para estrangeiros têm feito do emprego das várias formas de tratamento.

Refere-se ainda o modo de aquisição desse sistema e conclui-se com algumas sugestões para minorar as dificuldades que o ensino/aprendizagem do uso correcto das formas de tratamento em Língua Portuguesa acarreta.

Palavras-chave: formas de tratamento, ensino/aprendizagem da língua portuguesa, textos didácticos, Português, (in)delicadeza

${ }^{1}$ Este texto não segue o Acordo Ortográfico da Língua Portuguesa de 1990. Houve supervisão da Prof ${ }^{a}$ Doutora Maria da Conceição Carapinha Rodrigues, especialista em Pragmática Linguística. 


\section{Abstract: \\ Acquisition and Use of Forms of Address in Portuguese as a Foreign Language}

The main purpose of this text is to analyse the complex system (and use) of the forms of address and how it is presented to learners of Portuguese as a foreign language.

After a brief, and mainly theoretical, consideration about politeness in Linguistics, social deixis and its relation to the forms of address, this system of forms in Portuguese (European and Brazilian) is presented, as a starting point for the analysis of the kind of description that Grammars and didactic materials for foreigners usually do when they refer to the use of the various forms of address.

The acquisition of this system and the way it is transmitted are also referred. The text concludes with some suggestions in order to make it easier the teaching / learning of the correct use of these forms in Portuguese.

Keywords: forms of address, Portuguese language teaching and learning, didactic texts, Portuguese, un(politeness)

\section{Cortesia, Dêixis Social e Formas de Tratamento}

Observa Rodrigues (2003: 279) que "as práticas discursivo-textuais de quem realiza actos de comunicação" são "vigiadas" pela (des)cortesia. Essa vigilância é evidente no uso das formas de tratamento, ligadas a regras de etiqueta de tipo verbal.

Dos parâmetros de Leech (1983), à análise dos enunciados (des) corteses interessam o grau de familiaridade entre os falantes, a distância social e a autoridade, uma vez que a "primeira função dos tratamentos corteses é (...) de natureza relacional.” (Rodrigues, 2003: 279). A cortesia é, assim, uma competência comunicativa e social do falante, que lhe permite saber que certos "contextos situacionais requerem da sua parte um comportamento linguístico e social mais formal" do que outros. (Gouveia, 1996: 409).

Deste modo, a cortesia / delicadeza determina, linguisticamente falando, o emprego de determinadas estruturas, expressões e estratégias comunicativas de respeito, deferência, entre outras, numa "negociação" entre os interlocutores.

Para Levinson (1983: 89) as dêixis social e pessoal estão intimamente associadas dados os papéis de locutor/interlocutor, a relação 
social e o estatuto de cada um: há, pois, uma relação binária entre formalidade/informalidade, afectividade/neutralidade, proximidade/ distância, hierarquia e idade dos interlocutores. Por sua vez, a dêixis social de tipo relacional tem a ver com a relação (afectiva ou profissional) que se estabelece entre os interlocutores e a forma como é linguisticamente codificada. Está, assim, associada à cortesia.

Como nota Duarte (2011: 97), o emprego das formas de tratamento é determinado, de forma muito rígida, sobretudo no Português europeu, pela "distância social entre os interlocutores". A sua complexidade cria múltiplas dificuldades, na sua maior parte "de tipo pragmático e decorre de o locutor não saber adequar a forma própria ao destinatário que com ele se relaciona social e linguisticamente." (Duarte, 2011: 85)

\section{O sistema das Formas de Tratamento}

Pode ser considerado sob vários critérios ${ }^{2}$ : morfológico ${ }^{3}$ - formas pronominais tu/você ${ }^{4} /$ vocês/Va Ex. ${ }^{a} /$ vós), nominais (o(s) senhor(es)/a(s) senhora(s), a menina, etc.) e verbais (pronome nulo: Quer? Podem?); sintáctico: sujeito, vocativo ou objecto; referência enunciativa: alocutivos, delocutivos ou elocutivos; semântico-lexical: nome próprio ou diminutivo, nome de afecto (querido); nome profissional (professor, ministro $)^{5}$; semântico-pragmático: formas de intimidade, familiaridade, distância, respeito, poder, solidariedade, proximidade, afectividade, (in)formalidade ou hierarquia.

${ }^{2}$ Sobre as obras que versam sobre o tema em causa, veja-se Rodrigues (2003, cap. X: 291 e segs.).

${ }^{3}$ Vejam-se Rodrigues (2003: 283-284) e Cintra (1986: 12-13).

${ }^{4}$ Cintra (1986: 15) especifica que "você" se usa "no tratamento de igual para igual (ou de superior para inferior) e que não implica intimidade".

${ }^{5}$ Ao nível de semântica lexical ainda: nome de parentesco (a mãe, o avô, etc.); titulo nobiliárquico (Príncipe, Alteza Real, (Sr.) Visconde); títulos honoríficos (Vossa Santidade, Vossa Eminência, Sr. Comendador); Senhor /a, Dona; nomes de relação especial (camarada, vizinha, o patrão, o meu amigo, etc.); e insultos (fundamentalmente descorteses). 
Mas, mais complexo do que a variedade de formas em Português ${ }^{6}$, é o seu emprego na interacção comunicacional e a adequação ao contexto e ao estatuto do interlocutor, para evitar descortesia, o que é difícil sobretudo para os aprendentes estrangeiros.

\section{Casos "problemáticos" das Formas de Tratamento}

Ainda que tenha havido uma evolução e reestruturação secular das formas de tratamento, com alteração da sua função, não apenas em Português, mas nas várias línguas românicas ${ }^{7}$, uma gradual democratização da sociedade, de altamente hierarquizada para esbatimento das diferenças sociais, conduziu paulatinamente a uma mudança profunda nas formas de tratamento e a maior proximidade entre os locutores. Do tratamento, antes binário, de Sr. ${ }^{\mathrm{a}}$ Maria vs. Sr. ${ }^{\mathrm{a}} \mathrm{D}$. Maria, sendo o primeiro destinado a uma pessoa de condição social menor do que a que se trataria por Senhora Dona, de estatuto sociocultural/económico superior, usa-se mais hoje D. Maria para ambos os casos. É usual agora $\mathrm{Sr}^{\mathrm{a}}+$ nome ou até $\mathrm{Sr}^{\mathrm{a}}{ }^{+}$nome e apelido $^{8}$ ( $\mathrm{Sr}^{\mathrm{a}}{ }^{\mathrm{a}}$ Maria Gouveia) embora criticado sobretudo em nível sociocultural elevado.

Gouveia (2008) observa que o tratamento de Vossa Excelência está a cair em desuso (salvo para o Presidente da República, Embaixadores, etc.), e você está a sobrepor-se a o/a Senhor/a (embora no tratamento de filhos para pais esteja a ser substituído por $t u$ ). Vós, tratamento de segunda pessoa plural, confina-se geograficamente a algumas zonas de

\footnotetext{
${ }^{6} \mathrm{Na}$ história do Português, partiu-se de tu/vós até um variado leque de formas. Cf. Cintra, 1986 e Luz, 1958.

${ }^{7}$ A forma vos, em Latim, foi usada inicialmente para o Imperador, uma vez que havia dois no Império Romano (em Constantinopla e Roma), ganhando assim uma dimensão de poder, e utilizado de inferior para superior, enquanto que a similaridade social era dada por $t u$., estrutura bastante semelhante à do Francês contemporâneo. Para as formas de tratamento nas línguas românicas ver, por ex., Manole, 2012 e Oliveira, 2009 (mais concretamente sobre os pronomes de segunda pessoa em Português e Espanhol).

${ }^{8}$ Parece haver, em empresas de marketing e empresas estrangeiras em geral, "transposição" do uso do Inglês: Mrs. (+ nome) + apelido.
} 
Portugal (ex. nordeste trasmontano e distrito da Guarda) e a géneros textuais específicos (oratória e textos religiosos). Aliás, você é problemático (mas não vocês quando se trata do plural de $t u)^{9}$ : constitui ainda, em muitas zonas do país, uma forma de tratamento para uma relação assimétrica, pois é usado de superior para inferior. Contudo, conforme as regiões, pode ser sentido como respeitoso ou ofensivo: nota Hammermüeller (2004) que, em variedades mais próximas da Norma, você é grosseiro e inadmissível: "você é estrebaria!"10, diz-se em Coimbra, como repúdio ao emprego desta forma de tratamento; noutras consideram-no de igual para igual (usual na região lisboeta) e é frequente em publicidade e na televisão como tratamento de distância com alguma formalidade.

\section{Formas de Tratamento na norma brasileira}

São sobretudo Você e o/a Senhor/a (Senhorita é equivalente a Meni$n a$, para uma jovem e/ou solteira). Note-se que Você é o tratamento informal (por vezes reduzido a "cê"), sem qualquer deferência, como o $T U$ usado em Portugal. Contudo, o tratamento por $t u$ - na norma brasileira - só subsiste nas formas oblíquas te, $t i$, mas ainda se atesta regional ou informalmente ${ }^{11}$.

O grau de parentesco também é tratamento (mamãe, papai, titio/a, etc.) e é cada vez mais comum as crianças brasileiras usarem você para os pais (Silva, 2010) em vez do mais antigo o senhor/a senhora. Já

${ }^{9}$ A forma você deriva de outra, usada respeitosamente de inferior para superior, normalmente benfeitor de quem falava (e, portanto, agradecia-se a ajuda, a mercê): Vossa Mercê. A evolução para a forma mais curta teve outra intermédia (vossemecê), ainda usada em meios rurais, por ex. no Alentejo.

${ }^{10}$ A estrebaria é o local onde se guarda e cuida dos cavalos, local pouco asseado, pelo que esse uso é considerado típico de pessoas grosseiras, mais habituadas a lidar com animais do que com humanos. Em suma, quer dar-se a entender, com a referida expressão, que o emprego de "você" é inadequado e pouco cortês.

${ }^{11} \mathrm{Tu}$, à parte o seu emprego regional, usa-se acompanhado de $3^{\mathrm{a}}$ pessoa em vez de $2^{\text {a }}$ (Tu vai, tu viu, tu sabe...). Mesmo em falantes cultos, em situações de familiaridade ou coloquialidade. Agradeço esta informação ao Prof. Doutor Jerzy Brzozowski (Univ. Jaguelónica de Cracóvia). 
o tratamento de Doutor é usado para qualquer licenciado (ainda que engenheiro/a ou arquitecto/a) e, em meios socialmente desfavorecidos, para o homem que aparenta poder económico, mesmo sem formação académica. Também é mais usual o emprego do tratamento por cargo (Deputado, Ministro, Presidente) não antecedido de Senhor/Senhora, inversamente ao que ocorre em Portugal. O sistema brasileiro é, assim, menos hierarquizado e mais informal do que o do Português europeu.

Ainda que a norma ensinada nos países africanos de língua oficial portuguesa siga a de Portugal, é pertinente considerar brevemente o uso de algumas formas de tratamento nesses territórios, uma vez que se verificam diferenças significativas na língua quotidiana. Sobretudo entre os jovens, o que anuncia uma futura mudança, é cada dia mais frequente, em Angola e Moçambique, o uso de você como tratamento de informalidade, mas com a $2^{a}$ pessoa do singular: "Você que lutas", por exemplo. Noutros casos, perde-se a distinção você/tu: "Tu vais e tu vê...". Em Cabo Verde, o sistema é binário, com $t u$ informal e você para tratamento de respeito. A construção das várias normas dos países africanos ${ }^{12}$, que se encontra em curso, e a influência das línguas nacionais e/ou crioulos, certamente virão acarretar mais diferenças neste campo, ainda que haja alguns pontos comuns com o uso brasileiro.

\section{As Formas de Tratamento nos manuais didácticos de PLE}

O corpus que se recolheu para análise foi seleccionado tendo em conta que os manuais e auxiliares didácticos em apreço são os mais frequentemente utilizados, nas Universidades de Portugal, para o ensino do Português como língua não materna. Ainda que alguns tenham sido publicados há mais de 10 anos, não sofreram actualização (à parte, em muitos casos, da ortografia estabelecida pelo Acordo Ortográfico da Língua Portuguesa entretanto vigente) no que às formas de tratamento diz respeito.

Na Gramática de Arruda (2000: 110-112 e 2014: 113-114) explica-se que Tu é "forma de intimidade no Português europeu", enquanto

\footnotetext{
${ }^{12}$ Ver, entre outros, Nascimento, 2008.
} 
Você se usa no Brasil. Em Portugal "generalizou-se esta forma no tratamento de igual para igual, ou de superior para inferior (em idade, classe social ou hierarquia). Não é possível usar você de inferior para superior em idade, classe social ou hierarquia." (p. 111) ${ }^{13}$.

$O / A$ Senhor/a são formas de respeito e cortesia, que se opõem a tu e você. Para quem possui um título profissional ou cargo, estas formas são acompanhadas do respectivo cargo ou título: o senhor doutor 14, a senhora arquitecta. Diz: "[c]om menos respeito que a forma anterior", o doutor, a arquitecta. Para "certa proximidade", também o nome próprio ou apelido: o doutor João, "a arquitecta Melo" ("arquiteta" na versão de 2014). Mas não explica que é raro o tratamento de profissão com apelido para senhoras, salvo se há que distinguir entre várias com o mesmo nome próprio: $\mathrm{Dr}^{\mathrm{a}}$ Isabel Santos/Pereira, etc.

Menciona-se ainda Vossa Excelência (V. Ex. $\left.{ }^{a}\right)$, empregue em certos ambientes (Diplomacia, Governo), e cuja abreviatura "é bastante usual, principalmente na correspondência oficial e comercial"; Vossa Eminência (V. Em. $\left.{ }^{\mathrm{a}}\right)$, no discurso religioso para cardeais; Vossa Alteza (V. A.), para príncipes e duques; Vossa Majestade (V.M.), para reis e imperadores.

Considera outras formas usuais em Portugal antecedidas de artigo e exemplifica: nome próprio, de baptismo, ou de família (O José, O Silva); nomes de parentesco (O tio já veio?, A mãe quer sair); outros nomes que situam o interlocutor em relação a quem fala (A minha amiga, O patrão). Estranhamente não menciona os tratamentos de Dona e Senhora Dona, nem a forma verbal de sujeito nulo: Quer, Importa-se, etc., comuns na comunicação quotidiana.

Lemos (2000) e (2001), em diálogos e exercícios, refere Tu, Vocês, $O / A$ Senhor $/ a$ e respectivos plurais, $D$.(Dona), Sr. + nome, $D r$ e $D r{ }^{a}$ + nome, e formas verbais sem pronome ou forma nominal: Dê, Diga, Use, mas sem explicação concreta do emprego das formas.

${ }^{13}$ Os negritos são da minha responsabilidade.

${ }^{14}$ Doutor usa-se não só para os médicos, mas para "todos os diplomados por escolas superiores". 
Também o manual de Rosa (2004: 15-19) é omisso quanto ao emprego das formas de tratamento, mencionando-se Tu, o Senhor, Dona e Sr. Doutor, mas sem explicações de uso, o que é grave por ser de "auto-aprendizagem".

Oliveira e Coelho (2007: 65), ao tratarem da correspondência informal, usam colega, amigo e querido, sem especificação desse emprego. Parte-se, talvez, do princípio de que os aprendentes já dominam as formas básicas de tratamento expostas no tomo 1 do Curso (2006).

Avelar e Dias (2001: 16) alertam que "é importante tomar atenção ao uso das formas de tratamento em português de modo a evitar mal entendidos": $T U$, usado explícita e/ou implicitamente, é exclusivo do tratamento familiar e entre amigos de longa data; VOC $\hat{\boldsymbol{E}}$, usado explicitamente, está circunscrito a relacionamento informal entre colegas de profissão. Nos restantes casos, tende-se a usar a $3^{\mathrm{a}}$ pessoa verbal com ou sem pronome explícito ("o senhor pode ..., Sabe...". Com valor de vocativo não tem artigo e pressupõe o conhecimento do

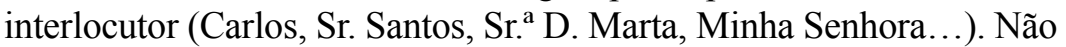
referem outros tratamentos menos frequentes.

Em Carmo (2004) os vários tratamentos surgem dispersos em textos (Tu / Vocês / O Senhor) ou em explicações pontuais, conforme as estruturas tratadas. Nas pp. 38-39 (Pronomes pessoais), Tu, Você / O Senhor, A Senhora /(Você), Vocês / os Senhores, as Senhoras, surgem sem explicação cabal, parecendo que podem assumir-se como equivalentes. Na p. 40, de novo você/o senhor/a senhora (com verbos regulares) e, na sugestão de uma actividade oral, questiona-se Você fala inglês? Na pág. 53, ao mencionar Senhor Artur, Senhor Morais, Dona Luisa, Senhora D. Luísa Morais, refere que "Você é recorrente, a par de o Senhor/a Senhora", sem explicar, como se fosse opcional e de idêntico grau de formalidade. Os títulos são referidos na p. 66 ( $\mathrm{Sr}$. e Sra. Doutor/a, arquitecto/a, director/a, presidente, embaixador/a, etc.) e, ao tratar das cartas formais/ informais (p. 226), inclui as formas verbais como meio de tratamento. Faltam explicações pormenorizadas, claras e coerentes, o que é susceptível de induzir em erro.

Em Oliveira, Ballmann e Coelho (2006: 152) explica-se o seguinte: $\mathrm{Tu}=$ pronome usado em comunicação informal (amigos, família, 
colegas), Você = pronome usado em qualquer domínio de comunicação (formal moderado), e designação/identificação através da forma verbal. Ao exemplificar, num caso de emprego de você (Onde é que você passou as últimas férias?), as Autoras alertam, e bem, para o facto de que "em algumas zonas do país a explicitação do pronome pessoal você antes do verbo pode ser socialmente desadequado, sendo preferível utilizar apenas a forma verbal".

Dias (2009: 205), num manual para aprendentes espanhóis, que têm um idioma de sistema binário ( $t u$ / usted), e com cada vez mais emprego de $T U$, não deixa clara a explicação dada para Você: Tu - situações informais e "Você - situações formais", como se fosse equivalente a Usted / Vosotros ou Vos, este último comum na América Latina.

Menciona-se ainda: o(s) / a(s) Senhores/as - podem ser usados em situações muito formais, como vocativos e ainda para referir uma terceira pessoa; D. Ana / Sr. António - em situações de comunicação directa usa-se D. (dona) ou Sr. (senhor) seguido do nome próprio; a forma masculina Dom só é utilizada para referir membros da reale$\mathrm{za}^{15}$; títulos académicos usualmente "precedidos, em situações muito formais, por senhor ou senhora ", artigo + nome próprio / apelido; também é comum usar-se só o verbo na $3^{a}$ pessoa; graus de parentesco; e outros: (minha querida, meu amigo, meu caro, etc.), mas a explicação carece, uma vez mais, de clareza e de indicações de índole sociolinguística e pragmática.

Henriques e Freitas (2004: 10-11) declaram, numa escala de informalidade para formalidade, que existem em Portugal várias formas de tratamento: TU (informal), normalmente com família, amigos e crianças. Pode-se usar com colegas ou pessoas conhecidas quando estas propõem o tratamento; VOCÊ (formal -), quando se conhece alguém e não há um grande grau de formalidade ou de informalidade. Se se sabe o nome da pessoa, é sempre preferível usá-lo; O/A SENHOR/A (formal +), quando não se conhece uma pessoa ou há um grande grau de formalidade. Para homens, usa-se o apelido, para

${ }^{15} \mathrm{Em}$ Espanhol ainda se usa D., em situações formais, para elementos do sexo masculino, mais idosos. 
senhoras usa-se DONA mais o nome próprio; TÍTULO ou POSIÇÃO (formal ++ ) - Dr. $\left({ }^{(a)}\right.$ - economistas, advogados, médicos, professores / Eng. $\left({ }^{\mathrm{a}}\right) /$ Arq. $\left({ }^{\mathrm{a}}\right) /$ Prof. $\left({ }^{\mathrm{a}}\right) /$ Director,a /Embaixador,a; O/A SENHOR/A + TÍTULO ou POSIÇÃO (formal +++). Completam a explicação alguns exercícios. Ainda que explicitem alguns usos, são pouco claros quanto ao grau de (in)formalidade no emprego de Você.

Em síntese, pela análise empreendida, verifica-se que as formas de tratamento não têm sido rigorosa e claramente explicadas em manuais didácticos para o ensino/ aprendizagem da Língua Portuguesa, sendo desejável que a este tema, tão complexo (para estrangeiros, sobretudo, mas ainda para falantes nativos ${ }^{16}$ ), se venha a dar a devida atenção, de modo a evitar situações desagradáveis e casos de descortesia.

\section{Aquisição das Formas de Tratamento e como minorar as dificul- dades do ensino/ aprendizagem desse sistema em PLE}

Normalmente a aquisição destas estruturas é feita na sala de aula, com o auxílio de manuais (ou em auto-aprendizagem), ou, não raras vezes, em contexto de inserção, essencialmente nos estrangeiros que se fixam em países de língua portuguesa por motivos profissionais.

Dado que o sistema de Formas de Tratamento em Português não é binário, é importante chamar a atenção dos aprendentes para esse facto, dando o inventário das formas existentes e explicando

${ }^{16}$ Está, de momento, em fase de divulgação de questionário para posterior análise um projecto de dissertação de Doutoramento sobre as formas de tratamento do Português contemporâneo, dando relevo ao uso real, adequação ao contexto, sensibilidade dos falantes e percepção de mudanças em curso. Importância especial está a ser dada a tu/vocêlo Senhor, a Senhora / vós. Esse inquérito / questionário foi divulgado através do Prof. Doutor Carlos Gouveia.

Seria de enorme utilidade proceder à elaboração de um outro questionário, desta vez destinado a alunos estrangeiros, de modo a perceber a sua percepção sobre o emprego do complexo sistema de formas de tratamento do Português, a distinção que fazem entre essas várias formas, e ajuizar da sua sensibilidade face a variações de uso(s). 
a complexidade que lhe é inerente se comparado com outras línguas, nomeadamente, Ing: you; Fr: tu/vous, Esp: tú/usted, Al: du / Sie; It: tu / lei ou voi ; e também ternário em Rom: tu / dumneata (de uso limitado, como "você" em Português) / dumneavoastră, etc.. Há, portanto, diferenças claras, como o não ser normal o uso de Dr. ${ }^{a}$ Gouveia ou Sr. ${ }^{a}$ Vilaça, e sim de Dr. ${ }^{a}$ Lucília (Gouveia) ou ( $\left.\mathrm{Sr}^{\mathrm{a}}\right)$ D. Luísa (Vilaça).

O uso das Formas de Tratamento está, portanto, sujeito a variação diatópica, diastrática e diacrónica, bem como a adequação ao contexto comunicativo.

Torna-se, então, imperioso fornecer aos aprendentes uma explicação exacta dos usos conversacionais / orais e da escrita (é, aliás, importante clarificar bem as diferenças de uso oralidade / escrita e as fórmulas adequadas a cada uma), acompanhando essa descrição/explicação de várias possibilidades de exercícios práticos.

Impõe-se ainda uma sensibilização para os casos "problemáticos" (nomeadamente o emprego de você, mas não exclusivamente ${ }^{17}$ ) e recomenda-se vivamente a inserção do aprendente num contexto em que se possam empregar as várias formas de tratamento; audição de conversas e situações em que se utilizam essas formas; tarefas para prática e teste desses usos (por ex. entre pessoas que não se conhecem, com a mesma idade e idades diferentes; entre pessoas que se conhecem, mas não são muito próximas, relacionamento de distância; relacionamento com superior hierárquico / profissional; entre adulto e criança; entre colegas; num estabelecimento comercial, restaurante, etc.), bem como a leitura de textos literários, num nível mais avançado de proficiência, como também sugerem M. Aldina Marques (2010) e Isabel Duarte (2011: 97-98) ${ }^{18}$.

Com a crescente globalização e a mobilidade estudantil e profissional, importa ainda explicar as diferenças de uso entre as variantes

${ }^{17}$ Há portugueses que não sabem usar Vossa Alteza, Vossa Majestade ou Vossa Excelência: com Vossa se lhe falam directamente; com Sua se se lhe referem na terceira pessoa.

${ }^{18}$ Estes textos permitiriam, ainda, ter a percepção de formas que se perderam já, das que estão a cair em desuso, e - também - de outras formas menos utilizadas na linguagem quotidiana. 
cultas (portuguesa e brasileira do Português e, a médio prazo, a sua relação com as variantes africanas).

Uma vez que, como se provou, os manuais estão desadequados, na sua maioria, à aprendizagem de um correcto e pragmaticamente eficaz uso deste sistema de formas, deve o docente, em suma, facultar aos aprendentes uma progressão gradual, adequada às suas competências (ao seu nível de proficiência), em lugar de um ensino superficial deste tema, promovendo a prática de actividades directamente dirigidas para que o aprendente adquira e, sobretudo, compreenda todas as especificidades de emprego de cada uma das formas estudadas.

Partindo, no início da aprendizagem (nível A 1), de um sistema básico tripartido (TU / O SENHOR, A SENHORA / FORMA VERBAL COM PRONOME NULO), assim que o mesmo esteja absoluta e perfeitamente adquirido, poder-se-á, gradualmente, prosseguir para uma complexificação das formas existentes e suas particularidades de uso, providenciando a inserção do aprendente em vários contextos situacionais que lhe permitam entender, na íntegra, as variantes existentes e seu verdadeiro valor.

O professor deve ainda corrigir (explicando bem a adequação ao contexto e situação) todo e qualquer erro de uso, de forma a evitar um possível mal entendido, ou uma ofensa, aconselhando as formas menos susceptíveis de gerar eventuais conflitos e/ou situações de descortesia.

Finalmente, seria desejável que, na sequência do que tem sido demonstrado no presente texto, os manuais didácticos fizessem, no que ao ensino/aprendizagem das Formas de Tratamento diz respeito, um investimento eficaz na descrição do complexo sistema que caracteriza a língua portuguesa e, essencialmente, a variante europeia.

\section{Referências bibliográficas}

ARRUDA, L. (2000), Gramática de Português para estrangeiros, Porto Editora, Porto.

ARRUDA, L. (2014), Gramática de Português Língua Não Materna, 2 ed. ( $2^{\mathrm{a}}$ reimpressão), Porto Editora, Porto. 
AVELAR, A., DIAS, H. B. M., CASTELEIRO, J. M. (2001), Lusofonia. Curso Avançado de Português Língua Estrangeira, Lidel, Lisboa-Porto-Coimbra.

CARMO, L. (2004), Olá! Como está? Livro de Textos. Curso Intensivo de Lingua Portuguesa. A1/A2/B1/B2, Lidel, Lisboa-Porto-Coimbra.

CINTRA, L. F. L. (1986), Sobre «Formas de Tratamento» na Língua Portuguesa, 2 ed., Livros Horizonte, Lisboa.

DIAS, A. C. (2009), Entre Nós 1. Método de Português para hispano-falantes. A1/A2, Lidel, Lisboa-Porto-Coimbra. [Nova edição segundo o Acordo Ortográfico em 2011]

DUARTE, I. M. (2011), "Formas de tratamento em português: entre léxico e discurso", Matraga, 18(28). UERJ, Rio de Janeiro, pp. 84-101, https:// www.doi.org/10.12957/matraga.2011.26077.

GOUVEIA, C. A. M. (1996), "Pragmática” em: Faria, I. H. [et al.] (org.), Introdução à Linguística Geral e Portuguesa, Caminho, Lisboa, pp. 383-419.

GOUVEIA, C. A. M. (2008), “As dimensões da mudança no uso das formas de tratamento em Português Europeu" em: Duarte, I. M., Oliveira, F. (eds.), O fascínio da linguagem. Homenagem a Fernanda Irene Fonseca, FLUP, Porto, pp. 91-100.

HAMMERMÜLLER, G. (2004), Adresser ou éviter, c'est la question. Comment s'adresser à quelqu'un en portugais sans avoir recours à un pronom ou à une autre forme équivalente, [on-line] http://cvc.cervantes.es/obref/ coloquio_paris/ponencias/pdf/cvc_hammermueller - 12.09.2018.

HENRIQUES, T. S., FREITAS, F. (2004), Qual é a dúvida?, Lidel, Lisboa-Porto-Coimbra.

LEECH, G. N. (1983), Principles of Pragmatics, Longman, London-New York.

LEMOS, H. (2000), Comunicar em Português, Lidel, Lisboa-Porto-Coimbra. [Edição revista em Novembro de 2003]

LEMOS, H. (2001), Praticar Português. Nivel Elementar, Lidel, Lisboa-Porto-Coimbra. [Edição revista, e seguindo o Acordo Ortográfico, em 2013] LEVINSON, S. (1983), Pragmatics, Cambridge University Pres, Cambridge. LUZ, M. S. (1958), Fórmulas de Tratamento no Português Arcaico, Casa do Castelo Editora, Coimbra. 
MANOLE, V. (2012), “As formas de tratamento nas línguas românicas: alguns usos em situações de intercompreensão mediadas na internet" em: Degache, C., Garbarino, S. (eds.), Actes du Colloque IC2012. Intercompréhension: compétences plurielles, corpus, intégration, Université Stendhal, Grenoble.

MARQUES, M. A. (2010), "Formas de tratamento e construção da relação interpessoal em Contos da Montanha de Miguel Torga", Revista Galega de Filoloxía, 11, pp. 61-78.

NASCIMENTO, M.F.B., PEREIRA, L.A.S., BETTENCOURT, J., ESTRELA, A., OLIVEIRA, S., SANTOS, R. (2008), “Corpus África: as cinco variedades africanas do português", XXIII Encontro Nacional da Associação Portuguesa de Linguística, APL, Lisboa, pp. 373-384.

OLIVEIRA, C., BALLMANN, M. J., COELHO, M. L. (2006), Aprender Português. A1/A2. Curso inicial de Língua Portuguesa para Estrangeiros, Texto Editores, Lisboa.

OLIVEIRA, C., COELHO, M. L., CASTELEIRO, J. M., CAMPELO, A., FARIA, A. (2007), Aprender Português 2. B1. Curso elementar de Língua Portuguesa para Estrangeiros, Texto Editores, Lisboa.

OLIVEIRA, L.C. (2009), "A evolução e o uso dos pronomes de tratamento de segunda pessoa singular no Português e no Espanhol", Letra Magna: Revista Eletrônica de Divulgação Científica em Língua Portuguesa, Lingüistica e Literatura, 5(10).

PRATAS, S. A. P. (2017). As formas de tratamento e o ensino de português como língua não materna, Tese de Mestrado, FLUC, Coimbra.

ROSA, L. M. (2004), Vamos lá começar! Exercícios de vocabulário. A1/A2/ B1, Lidel, Lisboa-Porto-Coimbra.

RODRIGUES, D. F. (2003), Cortesia linguística: uma competência discursivo-textual (Formas verbais corteses e descorteses em Português), FCSH-UNL, Lisboa, pp. 279-392.

SILVA, L. A. da (2010), "Formas de tratamento: contraste entre Portugal e Brasil”, AL LÍMITE. I Congreso SEEPLU, Facultad de Filosofía y Letras, Editorial Avuelapluma, Cáceres, pp. 56-62. 